\title{
Изотопные отношения стронция в системе вода-порода пещеры Шульган-Таш (Капова)
}

\author{
Киселева Д.В. ${ }^{1}$, Шагалов Е.С. ${ }^{1,2}$, Червяцова О.Я. ${ }^{3}$, Окунева Т.Г. ${ }^{1}$, Солошенко Н.Г. ${ }^{1}$ \\ ${ }^{1}$ Институт геологии и геохимии им. ак. А.Н. Завариикого УрО РАН, Екатеринбург, kiseleva@igg.uran.ru \\ ${ }^{2}$ Уральский государственный горный университет, Екатеринбург \\ ${ }^{3}$ Государственный природный заповедник Шульган-Таш, д. Иргизлы, респ. Башкортостан
}

Аннотация. Изотопы стронция являются маркерами грунтовых вод и чувствительными трассерами процессов их смешения. Изотопный состав стронция в воде зависит только от растворения минералов и ионообменных реакций: при течении через водоносный горизонт вода постепенно приобретает ${ }^{87} \mathrm{Sr} /{ }^{86} \mathrm{Sr}$ отношение пород, с которыми взаимодействует. На основании изученных отношений ${ }^{87} \mathrm{Sr} r{ }^{86} \mathrm{Sr}$ в системе вода-порода пещеры Шульган-Таш определены три основных источника: современный региональный речной сток, атмосферные осадки и породы (известняк), слагающие гору, в которой образована пещера. Сложная схема включает два тренда смешения: тренд $a$ соединяет крайние члены ряда - воду р. Белая и известняк; тренд $b$ соединяет атмосферные осадки с известняками. Все вариации содержаний и изотопного состава стронция в новообразованиях пещеры зависят от вклада этих источников. Полученные данные могут быть использованы для характеристики геохимического фона при гидрологических и археологических исследованиях в районе пещеры.

Ключевые слова: взаимодействие вода-порода, изотопы стронция, карстовая пещера, Шульган-Таш (Капова).

\section{Sr isotope ratios in the water-rock system of the Shulgan-Tash (Kapova) Cave}

\author{
Kiseleva D.V. ${ }^{1}$, Shagalov E.S. ${ }^{1,2}$, Chervyatsova O.Ya. ${ }^{3}$, Okuneva T.G. ${ }^{1}$, Soloshenko N.G. ${ }^{1}$ \\ ${ }^{I}$ A.N. Zavaritsky Institute of Geology and Geochemistry, Ural Branch of the Russian Academy of Sciences, \\ Ekaterinburg, kiseleva@igg.uran.ru \\ ${ }^{2}$ Ural State Mining University, Ekaterinburg \\ ${ }^{3}$ Shulgan-Tash State Natural Reserve, Irgizly, republic of Bashkortostan
}

\begin{abstract}
Strontium isotopes are useful fingerprints of ground water and sensitive tracers of ground water mixing. Sr isotope composition of water is dependent upon only the dissolution of minerals and ion-exchange reactions: when flowing through an aquifer, water gradually acquires the ${ }^{87} \mathrm{Sr} /{ }^{86} \mathrm{Sr}$ ratio of rocks with which it interacts. Based on the studied ${ }^{87} \mathrm{Sr} /{ }^{86} \mathrm{Sr}$ ratios, three principal sources are identified in the water-rock system of the Shulgan-Tash cave: modern regional river runoff, atmospheric precipitation and rocks (limestone) that make up the mountain in which the cave is formed. The complex mixing scenario involves Sr contribution via two mixing trends: $a$ trend connects the end-members corresponding to the water from the Belaya river and limestone; $b$ trend connects atmospheric precipitation with limestone. All variations in the $\mathrm{Sr}$ content and isotope composition in the newly formed minerals are dependent upon the contribution of these sources. The data obtained can be used to characterize the geochemical background during hydrological and archaeological studies in the cave area.
\end{abstract}

Keywords: water-rock interaction, strontium isotopes, karst cave, Shulgan-Tash (Kapova) Cave.

\section{Введение}

Карстовая пещера Шульган-Таш (Капова пещера) - широко известный объект археологических исследований благодаря наскальным рисункам первобытного человека эпохи палеолита, открытым в 1954 г. А.В. Рюминым. Она расположена в одноимённом заповеднике «Шульган-Таш» на территории Бурзянского района республики Башкортостан, Россия. В районе пещеры протекает река Белая, собственно пещера расположена примерно в 150 м выше по течению её правого притока реки Шульган, которая вытекает из пещеры. Пещера представляет собой систему карстовых полостей протяженностью 3050 м, причем 782 м из них - подводные полости, амплитудой 165 м и объемом 180510 м $^{3}$, расположенных на трех гипсометрических уровнях (Ляхницкий и др., 2006, 2013). Пещера заложена в толще пелитоморфных серых известняков верхнего девона и нижнего карбона. 
Сульфатные породы в блоке карстующихся пород и в области питания подземной гидросистемы не известны (Ляхницкий, 2006).

Содержание стронция и отношение ${ }^{87} \mathrm{Sr} /{ }^{86} \mathrm{Sr}$ в подземных водах контролируется взаимодействием вода-порода в водоносном горизонте. Различия в ${ }^{87} \mathrm{Sr} /{ }^{86} \mathrm{Sr}$ отношении могут быть обусловлены первичным (атмосферным) привносом, различиями в минералогии пород, через которые проходит вода, а также характеристиками растворения минералов и временем взаимодействия воды и породы. Минералы в породе имеют различные отношения $\mathrm{Rb} / \mathrm{Sr}$, а, следовательно, различные изотопные отношения стронция (Lee et al., 2011). Поскольку изотопное фракционирование стронция при геохимических процессах можно считать пренебрежимо малым, отношения ${ }^{87} \mathrm{Sr} /{ }^{86} \mathrm{Sr}$ широко используются для исследования взаимодействия вода-порода в подземных, термальных и речных водах (Shand et al., 2009; Lee et al., 2011; Loges et al., 2012; Zieliński et al., 2018). Изотопный состав стронция в воде зависит только от растворения минералов и ионообменных реакций: при течении через водоносный горизонт вода постепенно приобретает ${ }^{87} \mathrm{Sr} /{ }^{86} \mathrm{Sr}$ отношение пород, с которыми взаимодействует (Frost, Toner, 2004). Изотопы стронция являются маркерами грунтовых вод и чувствительными трассерами процессов их смешения; их высокая точность позволяет идентифицировать даже малейшие вариации изотопного состава вод (Frost, Toner, 2004).

Цель работы - выявление закономерностей взаимодействия вода-порода в карстовой системе пещеры Шульган-Таш с использованием изотопных отношений стронция ${ }^{87} \mathrm{Sr} /{ }^{86} \mathrm{Sr}$.

\section{Материалы и методы}

В период полевых работ 2019 года проведён сбор образцов пород, карбонатных новообразованных агрегатов и подземных вод из различных водоёмов и водотоков в пещере Шульган-Таш, а также в ноябре 2019 года отобрана усредненная месячная проба атмосферных осадков (табл. 1). Для сопоставительных целей взята проба воды из реки Белая.

Пробоподготовка и анализ микроэлементного и изотопного состава стронция проведены в блоке чистых помещений с классами чистоты 6 и 7 ИСО (ИГГ УрО РАН, г. Екатеринбург). На всех стадиях анализа использовалась ультрачистая деионизованная вода из установки Arium $®$ pro (Sartorius) (18.2 МОм• $\left.\mathrm{cm}^{-1}\right)$. Все используемые кислоты дополнительно очищались методом дистилляции при температуре, не доходящей до точки кипения (sub-boiling distillation).

Измерения микроэлементного состава проведены на квадрупольном ИСП-масс-спектрометре NexION 300S (PerkinElmer). Все измерения проводились в режиме количественного анализа с построением градуировочных кривых (мультиэлементные стандартные растворы PerkinElmer Instruments).

Для изотопного анализа стронций из растворенных проб и воды был хроматографически выделен с использованием смолы Triskem Sr-Spec (Muynck et al., 2009). Элюирование осуществлялось в соответствии с (Streletskaya et al., 2017) согласно протоколу, адаптированному из (Horwitz et al., 1992).

Измерения изотопного состава стронция проводили на мультиколлекторном магнитосекторном масс-спектрометре с двойной фокусировкой Neptune Plus (Thermo Fischer) методом брекетинга (SSB) с использованием NIST SRM 987 (карбонат стронция). Для оценки правильности и долговременной воспроизводимости измерительной процедуры использовали стандарт изотопного состава стронция NIST SRM 987: ${ }^{87} \mathrm{Sr} /{ }^{86} \mathrm{Sr}=0.710266 \pm 8(1 \mathrm{SD}, \mathrm{N}=23)$.

\section{Результаты и обсуждение}

Результаты анализа содержания стронция и изотопного отношения ${ }^{87} \mathrm{Sr} /{ }^{86} \mathrm{Sr}$ в исследованных образцах приведены в таблице 1 . Соотношение ${ }^{87} \mathrm{Sr} /{ }^{86} \mathrm{Sr}$ и обратного содержания стронция $1 / \mathrm{Sr}$ приведены на рисунке 1.

Анализ данных таблицы 1 и рисунка 1 позволяет высказать предположение о наличии древней гидрологической системы с довольно сложной схемой смешения, обусловленной поступлением стронция как минимум из трех главных источников.

Первый - современный региональный речной сток, охарактеризованный на примере вод реки Белая, с максимальным ${ }^{87} \mathrm{Sr} /{ }^{86} \mathrm{Sr}$ отношением 0.71058 и с промежуточным содержанием стронция 0.2 мг/л. 
Второй - атмосферные осадки, характеризующиеся наименьшим ${ }^{87} \mathrm{Sr} /{ }^{86} \mathrm{Sr}$ отношением 0.70816 и наименьшим содержанием стронция 0.09 мг/л. Третий источник - вмещающие породы (известняки) с промежуточным изотопным отношением 0.70881 и максимальным содержанием стронция $1.09 \mathrm{мг/л.}$

Таблица 1. Изотопные отношения ${ }^{87} \mathrm{Sr} /{ }^{86} \mathrm{Sr}$ и содержание стронция, мг/л.

Table $1 .{ }^{87} \mathrm{Sr} /{ }^{86} \mathrm{Sr}$ isotope ratios and $\mathrm{Sr}$ content, $\mathrm{mg} / \mathrm{l}$.

\begin{tabular}{|c|l|l|l|l|}
\hline № & \multicolumn{1}{|c|}{ Состав пробы } & ${ }^{87} \mathrm{Sr} /{ }^{86} \mathrm{Sr}$ & $2 \mathrm{SE}, \mathrm{abs}$ & $\mathrm{Sr}$, мг/л \\
\hline 1 & Серый известняк & 0.70881 & 0.00002 & 1.087 \\
3 & Белые прожилки в известняке & 0.70873 & 0.00002 & 1.065 \\
4 & Кальцитовые натечные коры & 0.71034 & 0.00006 & 0.859 \\
5 & Кальцитовый мондмильх, зал Хаоса & 0.70990 & 0.00006 & 0.258 \\
6 & Кальцитовый мондмильх, Верхний зал & 0.70963 & 0.00002 & 0.110 \\
7 & Гипсовые коры, зал Вестибюль & 0.70976 & 0.00004 & 2.643 \\
8 & Инфильтрационные воды, зал Хаоса & 0.70916 & 0.00002 & 0.242 \\
9 & Инфильтрационные воды, Верхний зал & 0.70906 & 0.00004 & 0.182 \\
10 & Дальнее озеро & 0.70916 & 0.00004 & 0.258 \\
11 & Карстовый источник Голубое озеро & 0.7089 & 0.00002 & 0.403 \\
12 & р. Белая & 0.70950 & 0.00004 & 0.331 \\
13 & Атмосферные осадки, ноябрь 2019 & 0.71058 & 0.00004 & 0.198 \\
\hline
\end{tabular}

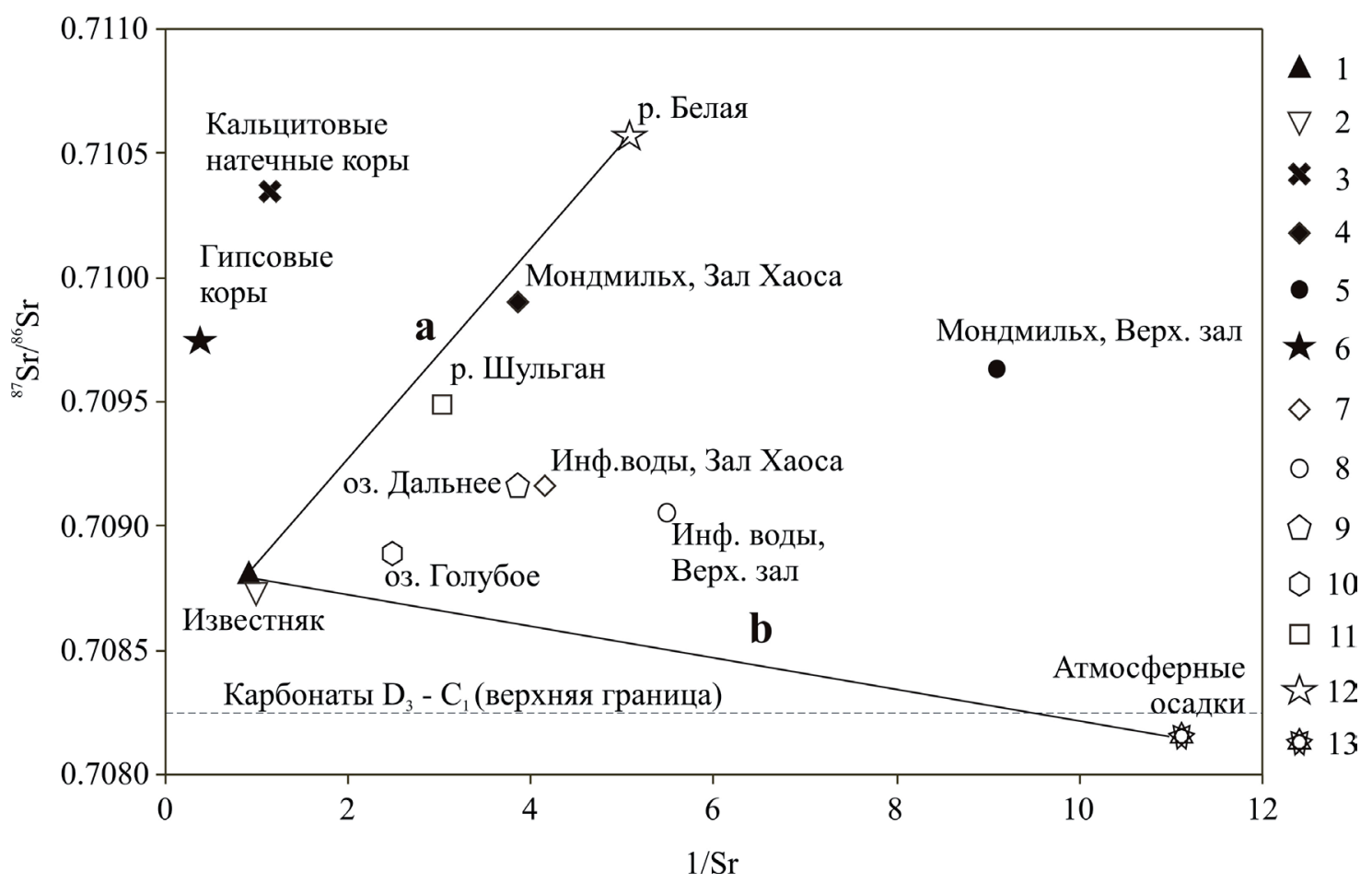

Рис. 1. Соотношение ${ }^{87} \mathrm{Sr} r{ }^{86} \mathrm{Sr}$ и $1 / \mathrm{Sr}$ в исследованных образцах. Условные обозначения соответствуют номерам проб в таблице 1. Для сравнения нанесена верхняя граница карбонатов верхнего девона и нижнего карбона (которые не расчленены для массива пещеры) (McArthur et al., 2001).

Fig. $1 .{ }^{87} \mathrm{Sr} /{ }^{86} \mathrm{Sr} v s 1 / \mathrm{Sr}$ in studied samples. Legend corresponds to the sample numbers in Table 1. Upper limit of Upper Devonian and Lower Carboniferous carbonates (which are nor subdivided for the cave rocks) are given (McArthur et al., 2001). 
На тренде смешения $а$ лежит точка р. Шульган (характеризующей локальный речной сток), занимающей промежуточное положение $\left({ }^{87} \mathrm{Sr} /{ }^{86} \mathrm{Sr}=0.70950\right)$ между крайними членами ряда - региональным речным стоком и известняком пещеры. Тренд $b$ соединяет атмосферные осадки с известняками. Все подземные воды из различных водоёмов и водотоков в пещере по изотопному отношению ${ }^{87} \mathrm{Sr} /{ }^{86} \mathrm{Sr}$ и содержанию стронция укладываются в диапазоны между указанными источниками.

Изотопное отношение в капели с верхнего этажа (0.70906), пониженное по сравнению с капелью из Зала Хаоса (0.70916), можно объяснить бо́льшим влиянием разбавления водой атмосферных осадков, чем на нижних этажах, при котором уменьшается как содержание стронция, так и его изотопное отношение. Это же утверждение справедливо и для монтмильха из разных залов (содержание стронция составляет 0.26 мг/л в Зале Хаоса и уменьшается до 0.11 мг/л в Верхнем Зале). При этом различие в ${ }^{87} \mathrm{Sr} /{ }^{86} \mathrm{Sr}$ довольно небольшое (0.70990 и 0.70963), но ниже в Верхнем зале.

Дальнее озеро по содержанию стронция (0.26 мг/л) и его изотопному отношению (0.70916) располагается близко к капели из Зала Хаоса, что может свидетельствовать об их гидрохимической однородности. Голубое озеро, расположенное в гроте перед входом в пещеру, имеет ${ }^{87} \mathrm{Sr} /{ }^{86} \mathrm{Sr}=0.7089$ и содержание стронция 0.4 мг/л, что может быть обусловлено совместным действием двух факторов: длительным временем нахождения воды в известняке и влиянием атмосферных осадков.

Белые прожилки кальцита в известняке, характеризуются близким изотопным составом и содержанием стронция (0.70873 и 1.07 мг/л, соответственно), что может свидетельствовать о довольно быстром процессе растворения-осаждения вторичного карбоната.

Кальцитовые коры характеризуется максимальным среди пород изотопным отношением ${ }^{87} \mathrm{Sr} /{ }^{86} \mathrm{Sr}=0.71034$ и минимальным содержанием стронция 0.86 мг/л, что говорит о более длительной кристаллизации и, возможно, последующей перекристаллизации с выносом первичного известнякового стронция и замещением более радиогенным стронцием вследствие длительной переработки подземными водами с изотопной меткой вод регионального речного стока.

Гипсовые коры со стен имеют максимальное содержание стронция 2.6 мг/л и промежуточный изотопный состав (0.70976) между породами и водой р. Белая, при этом более радиогенный, чем в р. Шульган. Ранние исследования (Червяцова и др., 2018) показали, что гипс кристаллизовался в условиях более сухого и холодного климата, и по изотопному составу серы его происхождение может быть обусловлено либо древним испарительным насыщением природных карстовых вод сульфат-анионом, либо точечной сернокислотной коррозией при локальном окислении сульфидных минералов вмещающих известняков (Ляхницкий, 2006).

\section{Выводы}

На основании изученных отношений ${ }^{87} \mathrm{Sr} /{ }^{86} \mathrm{Sr}$ в системе вода-порода пещеры Шульган-Таш определены три основных источника: современный региональный речной сток, атмосферные осадки и породы (известняк), слагающие гору, в которой образована пещера. Сложная схема включает два тренда смешения: тренд $a$ соединяет крайние члены ряда - воду р. Белая и известняк; тренд $b$ соединяет атмосферные осадки с известняками. Все вариации содержаний и изотопного состава стронция в новообразованиях пещеры зависят от вклада этих источников. Полученные данные могут быть использованы для характеристики геохимического фона при гидрологических и археологических исследованиях в районе пещеры.

Работа выполнена в ЦКП УрО РАН «Геоаналитик» при финансовой поддержке РФФИ, грант № 20-09-00194.

\section{Литература}

1. Ляхницкий Ю.С. Многолетние исследования пещеры Шульган-Таш (Каповой) группой ВСЕГЕИ и РГО как основа спасения ее палеолитической живописи // Изучение заповедной природы Южного Урала. Уфа. Изд-во: ООО Вилли Окслер. 2006. С. 331-382.

2. Ляхницкий Ю.С., Юшко А.А., Минников О.А. Рисунки и знаки пещеры Шульган-Таш (Каповой). Каталог. Уфа: «Китап». 2013. 288 с. 
3. Червяцова О.Я., Потапов С.С., Садыков С.А., Дублянский Ю.В., Мусабиров И.И., Демени А. К вопросу о генезисе субаэральных отложений гипса в пещере Шульган-Таш // Известия Уфимского научного центра РАН. 2018. № 1. С. 58-95.

4. Frost C.D. and Toner R.N. Strontium Isotopic Identification of Water-Rock Interaction and Ground Water Mixing // Ground water. 2004. V. 42(3). P. 418-432.

5. Horwitz E.P., Chiarizia R., Dietz M.L. A novel strontium-selective extraction chromatographic resin // Solvent Extraction and Ion Exchange. 1992. V.10. P. 313-336.

6. Lee S.-Gu, Kim T.-K., Lee T.J. Strontium isotope geochemistry and its geochemical implication from hot spring waters in South Korea // Journal of Volcanology and Geothermal Research. 2011. V. 208. P.12-22.

7. Loges A., Wagner T., Kirnbauer T., Göb S., Bau M., Berner Z., Markl G. Source and origin of active and fossil thermal spring systems, northern Upper Rhine Graben, Germany // Applied Geochemistry. 2012. V. 27. P. 1153-1169. DOI:10.1016/j.apgeochem.2012.02.024.

8. McArthur J.M., Howarth R.J. and Bailey T.R. Strontium isotope stratigraphy: LOWESS Version 3. Best-fit line to the marine Sr-isotope curve for 0 to $509 \mathrm{Ma}$ and accompanying look-up table for deriving numerical age. J. Geol. 2001. V. 109. P. 155-169.

9. Muynck D.D., Huelga-Suarez G., Heghe L.V., Degryse P., Vanhaecke F. Systematic evaluation of a strontiumspecific extraction chromatographic resin for obtaining a purified $\mathrm{Sr}$ fraction with quantitative recovery from complex and Ca-rich matrices // J. Anal. At. Spectrom. 2009. V. 24. P. 1498-1510.

10. Shand P., Darbyshire D.P.F., Love A.J. \& Edmunds W.M. Sr isotopes in natural waters: Applications to source characterisation and water-rock interaction in contrasting landscapes // Applied Geochemistry. 2009. V. 24(4). P. 574-586.

11. Streletskaya M., Zaytceva M., Soloshenko N. Sr and Nd chromatographic separation procedure for precise isotope ratio measurement using TIMS and MC-ICP-MS methods. Abstracts of European winter conference on plasma spectrochemistry (EWCPS-2017). Sankt-Anton am Arlberg. 2017. P. 319.

12. Zieliński M., Dopieralska J., Belka Z., Walczak A., Siepak M., Jakubowicz M. Strontium isotope identification of water mixing and recharge sources in a river system (Oder River, central Europe): A quantitative approach // Hydrological Processes. 2018. P. 1-15. DOI: 10.1002/hyp.13220. 